\title{
A study of clinical profile and management of dominant thyroid nodule in a tertiary care hospital of West Bengal
}

\author{
Nibaran Mandal', Shib Shankar Kuiri², Mintu Mohan Nandi², Bikash Chandra Ghosh ${ }^{3}$, \\ Goutam Ghosh ${ }^{4}$, Yash Sharma ${ }^{5}$ \\ ${ }^{1}$ R.M.O cum Clinical Tutor, Department of General Surgery, Murshidabad Medical College, West Bengal, ${ }^{2}$ Assistant \\ Professor, ${ }^{5}$ Resident, Department of General Surgery, Bankura Sammilani Medical College and Hospital, ${ }^{3}$ Associate \\ Professor, ${ }^{4}$ Professor and Head, Department of General Surgery, R.G. Kar Medical College and Hospital, West Bengal
}

\section{A B STR A C T}

Background: A dominant thyroid nodule (swelling) is a discrete swelling in a gland with clinical evidence of generalized abnormality in the form of palpable contra-lateral lobe or generalized mild nodularity. About $30 \%$ of thyroid nodules are dominant. The important aspect in evaluation of dominant thyroid nodule is to exclude malignancy. Aims and Objectives: 1) to determine incidence of dominant thyroid nodule in relation with age and sex. 2) to determine the functional status of thyroid in dominant nodule. 3) to determine role of FNAC to diagnose a case of dominant thyroid nodule 4) incidence of malignancy among dominant thyroid nodule cases. Materials and Methods: All patients attending surgery OPD at BSMCH between the study periods of August 2013 to July 2016 with clinically and radiologically proven dominant thyroid nodule were included in this study. Patients with solitary or recurrent nodules were excluded. Results: Total of 147 patients were included in his study, with $86 \%$ of them being female, mean age of presentation was $38.35 \mathrm{yrs}$, and commonest age group being $5^{\text {th }}$ decade. Only one patient had secondary hyperthyroidism. FNAC reports reveled $79 \%$ benign etiology, $16 \%$ malignant etiology, $4 \%$ intermediate etiology, $1 \%$ suspicious to be malignant. Sensitivity of FNAC was $73.3 \%$, and specificity $97.2 \%$ to diagnose malignant etiology. The frequency of malignancy was $21.1 \%$. Conclusion: Thyroid nodule is commonest presentation in various thyroid diseases mainly seen in females and in $5^{\text {th }}$ decade and presents as thyroid cyst, colloid nodule, thyroid neoplasm, and thyroiditis. USG and FNAC has established role in evaluation of the nature of thyroid nodule and its management. Pressure symptoms requires surgery. Toxic nodules are mainly treated with antithyroid drugs, radioactive iodine and occasionally surgery, but malignant thyroid nodule mainly treated with total thyroidectomy.

Key words: Dominant thyroid nodule, Incidence of thyroid nodule in female, Role of radiology and FNAC in evaluation and management of thyroid nodule.

\section{INTRODUCTION}

Enlargement of thyroid gland is most common manifestation of thyroid disease. The term goiter is used to describe generalized swelling of thyroid. On the other hand nodular swelling of thyroid described as "discrete lesion within thyroid gland, radiologically distinct from surrounding parenchyma."1 Nodular swelling is clinically important because of its malignant potential. Thyroid nodules can be detected by palpation in $10 \%$ of women and $2 \%$ of men. ${ }^{2}$ The prevalence of thyroid nodules can be $50 \%$ or more if ultrasonography was used. ${ }^{2}$ Thyroid cancer although most common endocrine malignancy but represents only $1 \%$ of all malignancies. ${ }^{2}$ The annual incidence of thyroid cancer in the UK was reported at 3.5 per 100,000 women and 1.3 per 100,000 men. ${ }^{3}$ NCRP data of 10 years from different populations of India revealed an overall incidence of thyroid cancer was $1.87 \%$ among different cancer patients, of which 
$64.3 \%$ were females. ${ }^{4}$ It is therefore crucial to have a clear diagnostic approach to ensure appropriate management so as to prevent over or under-treatment.

Nodular swelling may be two types: A) solitary nodule and B) Dominant nodule.

A dominant thyroid nodule is a discrete swelling in a gland with clinical evidence of generalized abnormality in the form of palpable contra-lateral lobe or generalized mild nodularity. About $30 \%$ of thyroid nodules are dominant. ${ }^{5}$ A dominant thyroid nodule is may cause thyroid dysfunctions, compressive symptoms but it is primarily important because of the need to exclude thyroid malignancy.

\section{MATERIALS AND METHODS}

This is an institutional based prospective study was conducted in General Surgery Department, Bankura Sammilani Medical College from August 2013 to July 2016. Study population was 147 patients attending outpatient department of surgery with clinically and ultrasonographically diagnosed dominant thyroid nodule.

Four parameters were studied for evaluation of dominant thyroid nodules. Clinical study solely based on history and clinical examination. Thyroid Function Tests: Free T4 and free $\mathrm{T} 3$ were measured by radioimmunoassay and TSH was measured by immunoradiometric assay (IRMA). Glandular functional abnormalities were tested by measurements of serum TSH, total and free T4 and T3 levels to evaluate the pre-operative thyroid status of the patients.

\section{Ultrasonography}

USG was thus performed in all cases to measure the nodule size, number, condition of contralateral lobe and to distinguish cystic and solid lesions and on echogenic pattern, distinguish benign from malignant thyroid lesions. A nodule is characterized as hypoechoic, isoechoic, and hyperechoic or anechoic. Hypoechogenicity is associated with thyroid malignancy. FNAC: If done properly and with appropriate patient selection, the false negative rate is less than $5 \%$ and false positive rate of $1-5 \%$. It has a sensitivity of $83 \%$ and specificity of $92 \%$.

All patients attending outpatient department of surgery in the period of 3 years with palpable and ultrasonographically proved dominant thyroid nodule greater than one centimeter in size were randomly included in this study group. After obtaining informed consent from a adult patient and from parents of minor patients was further assessed clinically. Then cytological evaluation done by fine needle Aspiration Cytology. According to FNAC reports all patient was managed accordingly and post operative outcome by means of complications and recovery was documented. Histopathological report of operative specimen was obtained from pathology department.

Total 147 patients were included in this study.patients were grouped according to different variable like age, sex occupation, duration of symptoms, size of the nodule, lobe affected predominantly, functional thyroid status, FNAC reports, treatment given, histopathological reports, post operative complications.

The outcome is analyzed and compared according to standard statistical test to find out significant factor and predictability using excel software. The diagnostic statistics were carried out to find the diagnostic value of FNAC for Benign and Malignant lesions in relation with Histopathological results.

\section{RESULTS}

In this study ages of the patients ranges from 15 years to 66 years. With peaks being $3^{\text {rd }}$ and $5^{\text {th }}$ Decades.

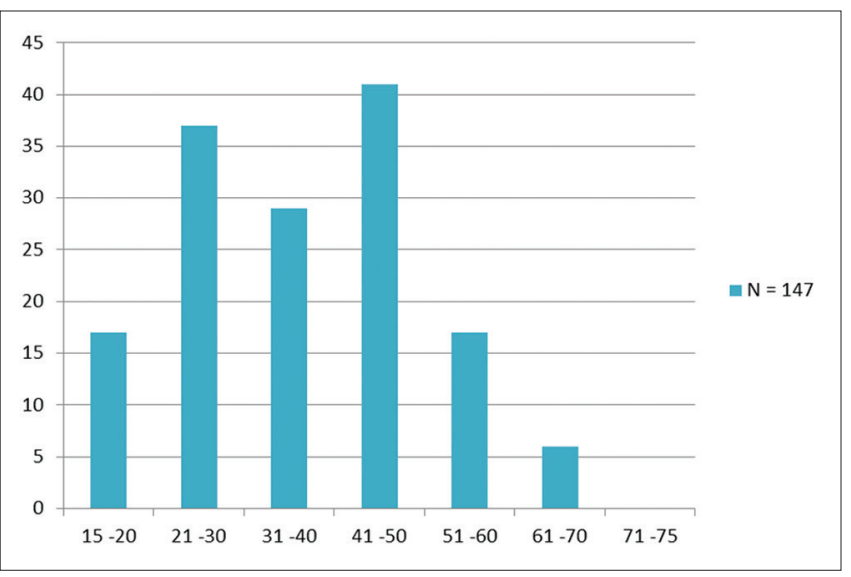

Dominant thyroid nodule more common in females in this study. Out of 147 patients 126 were female and 21 male patients, M: F ratio becomes 1:6. As most of the patients of this study are females so $75 \%$ of patients are house wife in occupation, $10 \%$ are students, $8 \%$ are farmer, 6 $\%$ are laborer, and $1 \%$ is businessman in occupation. All 147 patients came to us with chief complaints of swelling, which may or may not associate with others symptoms. Twenty three patients came to us with pain along with swelling of thyroid region. Six patients complained about difficulty in swallowing along with swelling, 2 patients came to us with complain of bulging of eyes along with thyroid swelling, Only one patient complained about tremor and palpitation. In this study duration of symptoms ranges from 3 months to 8 years. Thirty five percent of patients presented symptoms within 2 years, $30 \%$ patients within 1 year and $27 \%$ patients present within 5 years. Most malignant nodules present within 1 year (67\%), one patient

Asian Journal of Medical Sciences | Jul-Aug 2017 | Vol 8 | Issue 4 
present after 4 years. Mean time period before presentation was 21.8 months. Dominant thyroid nodule located in isolated right lobe in 55\% of cases, in isolated left lobe in $27 \%$ cases, in isthmus $4 \%$ cases. Dominant nodule located more than one lobe with or without isthmus in $14 \%$ cases.

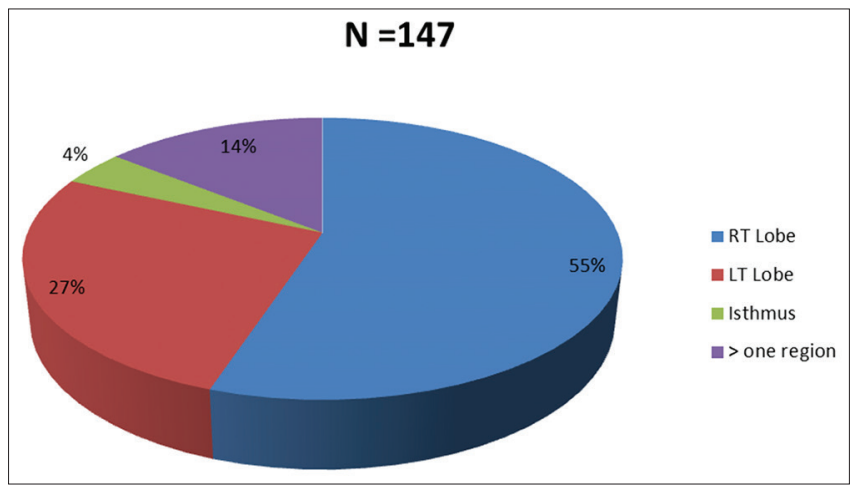

In this study $51 \%$ of nodule are less than $2 \mathrm{~cm}$. Dominant nodule measuring $2-4 \mathrm{~cm}$ constituted $45 \%$. Only $4 \%$ nodules are more than $4 \mathrm{~cm}$ in highest dimension.

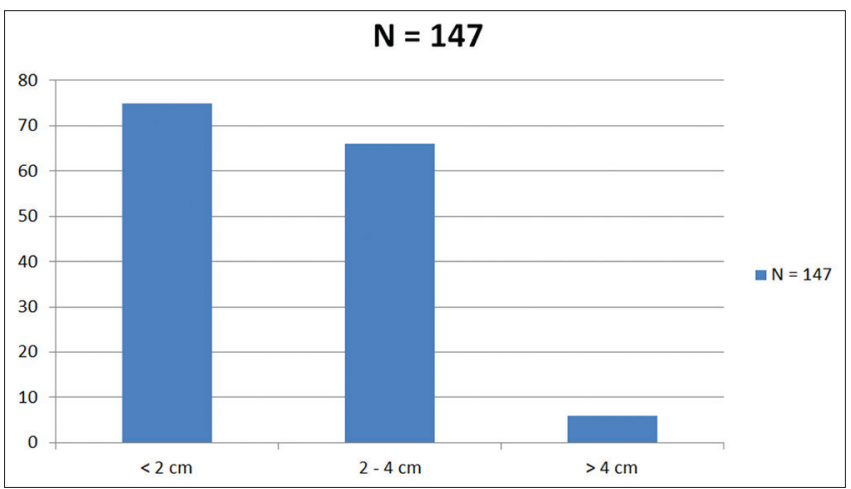

Most of the patients (87\%) presented with euthyroid state, $6 \%$ patient was in hypothyroid state and $7 \%$ patient was in hyper thyroid state.

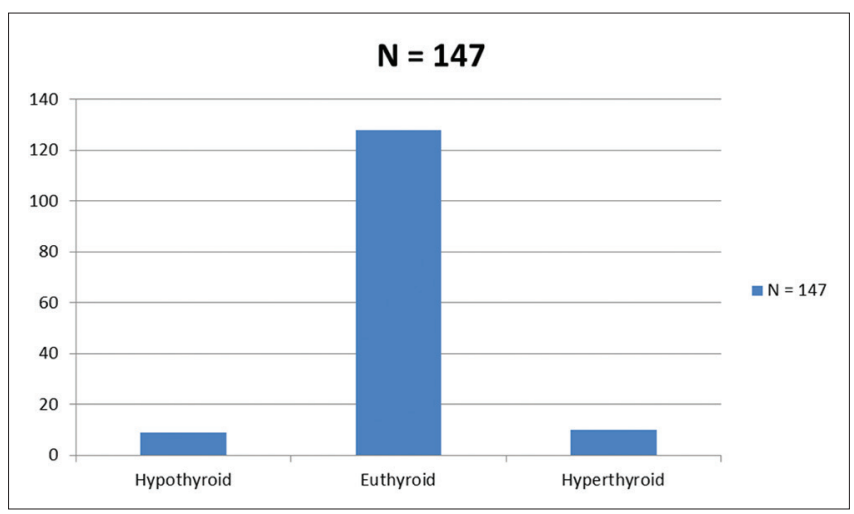

All 147 cases were categorized into 5 groups like benign, malignant, follicular neoplasm, Thyroiditis, suspicious to be malignant. In our study benign nodule in the form of adenomatoid goiter, colloid goiter was 73\%. Malignant nodule all were in the form of papillary carcinoma was $16 \%$. Three cases were diagnosed as follicular neoplasm (non diagnostic) and one turned to be follicular carcinoma. Six percent of all cases was thyroiditis. One case was diagnosed as suspicious to be malignant but turned into nodular goiter. In this study total 106 patients was underwent surgical procedure, among 106 patients 69 was underwent hemithyroidectomy (65\%), 12 was underwent subtotal thyroidectomy ( $8 \%$ ), Four Patients was underwent near total throidectomy (4\%), and total thyroitectomy done in 24 patients (23\%). In this study 106 patient was underwent surgery. Histopathogical report of these patient was as follows colloid goiter 19 in number $(18 \%)$, follicular adenoma 56 in number (53\%), papillary carcinoma 29 in number $(27 \%)$ and only two case was follicular carcinoma.

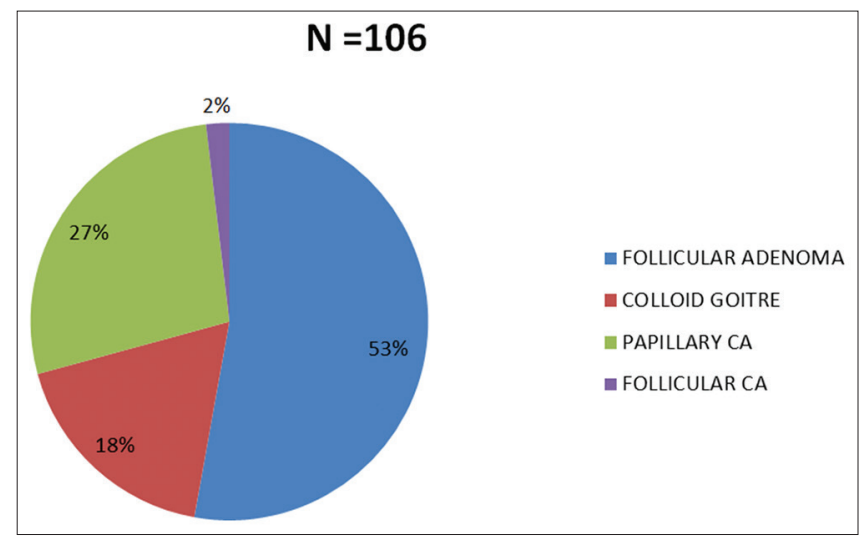

In this study sensitivity of FNAC to diagnose malignancy of dominant thyroid nodule was $73.3 \%$, And specificity was $97.2 \%$. Positive predictive value was $91.6 \%$ and negative predictive value was $89.7 \%$.

\begin{tabular}{lccc}
\hline FNAC & \multicolumn{2}{c}{ HPE } & Total \\
\cline { 2 - 3 } & Malignancy & Benign & \\
\hline Malignancy & 23 & 02 & 25 \\
Benign & 8 & 73 & 81 \\
Total & 31 & 75 & 106 \\
\hline
\end{tabular}

In this study $78.9 \%$ cases dominant thyroid nodule found to be benign and $21.1 \%$ found to be malignant.

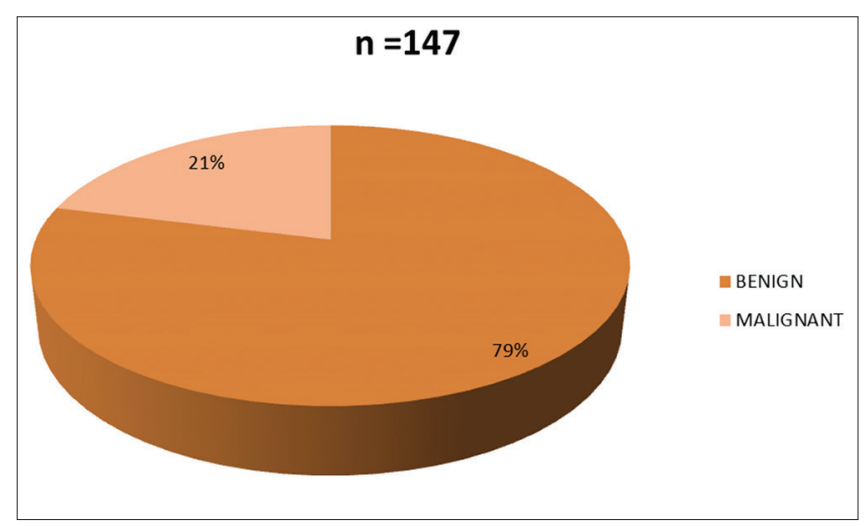


In this study benign disorder constitute $79 \%$ of 147 patients entitled in this study. commonest benign disorder found in this study is follicular adenoma(48\%), and colloid goitre (43\%), Thyroiditis ( $9 \%)$.

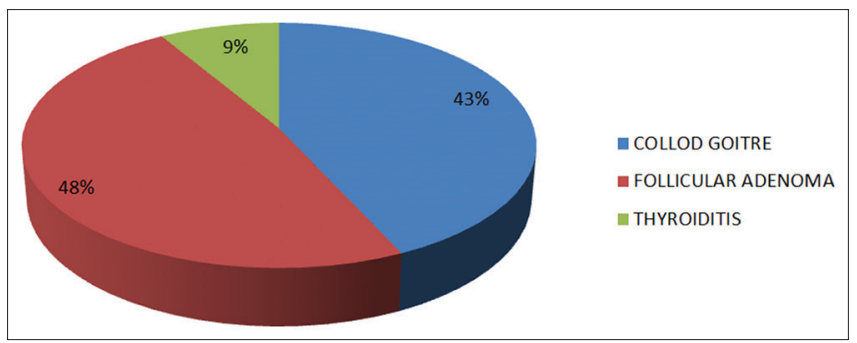

\begin{tabular}{lc}
\hline Aetiology & No. of patients $(\%)$ \\
\hline Papillary carcinoma & $29(93)$ \\
Follicular carcinoma & $02(7)$ \\
Total & $31(100)$ \\
\hline
\end{tabular}

In this study papillary carcinoma thyroid constitute 29 cases out of 31 malignant cause of dominant thyroid nodule. There were 2 patients of follicular carcinoma thyroid.

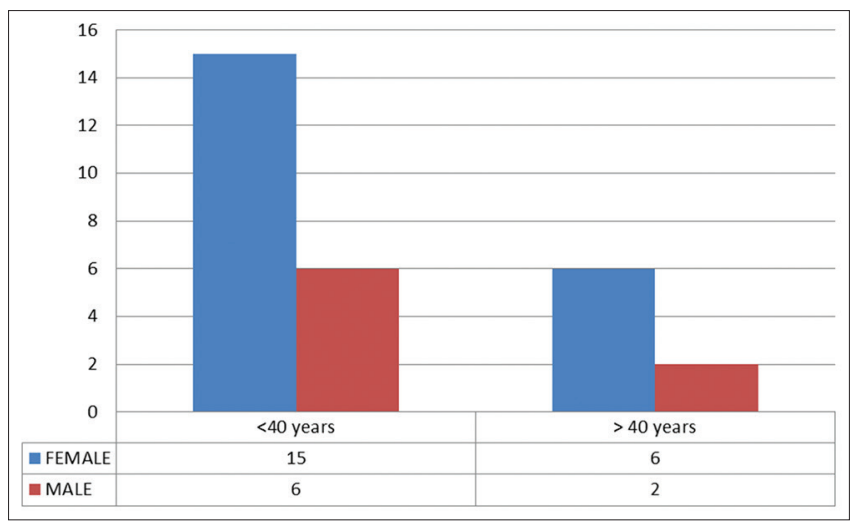

Total 21 female and 8 male were suffering from papillary carcinoma thyroid. $\mathrm{F}: \mathrm{M}=(2 \cdot 5: 1) .21$ patient was below 40 years, among them 15 were female and 6 male. 8 patients was above 40 years, among them 6 were female and 2 male. Most of the papillary carcinoma patient presented with stage I disease.

\section{DISCUSSION}

Nodular goitre is the one of the common Presentation of various thyroid diseases. Causes of dominant thyroid nodule are -thyroid cyst, colloid nodule, thyroid neoplasm, thyroiditis, infective.

Evaluation of dominant thyroid nodule is a stepwise procedure, initially proper history should be taken and adequate clinical examination should be carried out. Radiological evaluation is done by ultrasonography to correlate clinical findings. There is certain radiological features which suggest malignancy like irregular margin, presence of micro calcification, hypoechogenecity, absence of halo, complex cyst, intranodular vascularity. ${ }^{6}$ FNAC is widely accepted and become cornerstone in evaluation of thyroid nodules because it is simple and accurate screening tool with high sensitivity and specificity. ${ }^{7}$ Most patients presenting with a dominant thyroid nodule are euthyroid, and the simplest way to verify this is a serum thyrotropin (TSH) level. If below normal, the workup proceeds with total or free thyroxin (T4) and total triiodothyronine (T3) to better evaluate the hyperthyroid state. ${ }^{8}$

Management of throid nodule depends on cytology report. Benign nodule with normal thyroid function test does not require surgery. Surgery is indicated when there is a pressure symptom. Toxic nodules are treated by antithyroid drugs, radioiodine and occasionally surgery. Malignant nodules are treated surgically by means of total thyroidectomy.

In this study total 147 patients were analyzed. Highest peak of incidence of dominant nodular disorder noted in $5^{\text {th }}$ decade $(28.1 \%)$ and $3^{\text {rd }}(25 \%)$ of age group. But in almost similar type study conducted by Hanumanthappa.M.B. et $\mathrm{al}^{9}$ shows that peak incidence of multi nodular goitre is in $3^{\text {rd }}$ decade $(35 \%)$ and then $4^{\text {th }}$ decade $(30 \%)$. D. Shrestha et al shows in their study that peak incidence in $4^{\text {th }}$ decade $(50 \%){ }^{10}$

M: F ratio in previous almost similar type study shows 1:7.4 in study conducted by Prades JM et al, 1:5.6 in study conducted by Hanumanthappa.M.B. et al., In present study its found to be 1:6, which co-relates with previous study. ${ }^{11}$

Sensitivity of FNAC to diagnose malignancy in this study $(73.3 \%)$ is concurrent in comparison of previous study conducted by Ko HM Jhu Ik et al (78.4\%).but much better than another previous study conducted by Al-Hureibi KA et al $(38 \%) .{ }^{12,13}$ Specificity of FNAC in all three previous study are almost same.

The incidence of malignancy was highest in Melanie Goldfarb series being $42 \%$, while the least ulHaq RN series being $2.92 \%$. The incidence of malignancy in this study was $21 \%{ }^{14,15}$

\section{REFERENCES}

1. Cooper DS. Revised American Thyroid Association management guidelines for patients with thyroid nodules and differentiated thyroid cancer. Thyroid. 2009; 19(11):1167-214. [PubMed:19860577].

2. Ezzat S, Sarti DA, Cain DR, et al. Thyroid incidentalomas. Prevalence by palpation and ultrasonography. Arch Intern Med. 1994; 154(16):1838-40. [PubMed: 8053752]. 
3. British Thyroid Association, Royal college of Phrygians. British Thyroid Association Guidelines for the management of thyroid cancer.2.[online] 2007. URL: http://www.britishthyroid - association.org/Guidelines

4. Rao DN. Thyroid Cancer- An Indian Perspective. In: Shah AH, Samuel AM, Rao RS, editors. Thyroid Cancer- An Indian Perspective. Mumbai: Quest Publications; 1999; pp. 3-16.

5. Norman S. Williams Christopher J.K Bulstrode \& P. Ronan O'Connell: Short Practise of Surgery;26 th edition.

6. Frates MC, Benson CB, CharboneauJW, et al. Management of thyroid nodules detected at US: Society of Radiologists in Ultrasound Consensus Conference Statement. Radiology 2005;237:794-800

7. Arunkumar MM, Ahuja S, Chattopadhyay TK, Padhya AK, Gupta AK, Kapila K et al. FNAC, Sonography and Radionuclide Scanning in solitary thyroid nodule. J Asso Physicians India 1992, 40, 302.

8. Wong $\mathrm{CK}$, Wheeler $\mathrm{MH}$. Thyroid nodules: rational management. World J Surg 2000;24(8):934-41. [PubMed: 10865037].

9. Hanumanthappa MB, Gopinathan S, Suvarna R, RaiG, Shetty G, Shetty A, et al. The Incidence of Malignancy in Multi-nodular
Goitre: A Prospective Study at a Tertiary Academic Centre. Journal of Clinical and Diagnostic Research. Apr.2012; 6(2): 267-270.

10. D. Shrestha, S. Shrestha, The Incidence of Thyroid Carcinoma in Multinodular Goiter: A Retro-spective Study, Journal of College of Medical Sciences-Nepal, Vol-10, No 4, Oct-Dec 014.

11. Prades JM, Dumollard JM, Timoshenko A, Chelikh L, Michel F, Estour B, et al. Multi-nodular goitre: surgical management and histopathological findings. Eur Arch Otolaryngo/ 2002; 259:217-21.

12. Ko HM, Jhu IK, Yang SH, Lee JH, Nam JH, Juhng SW, et al. Clinicopathologic analysis of fine needle aspiration cytology of the thyroid. A review of 1,613 cases and correlation with histopathologic diagnoses. Acta Cytol. 2003 Sep-Oct; 47(5):727-32. Review.

13. Al-Hureibi KA,Al-HureibiAA, AbdulmughniYA,Aulaqi SM, Salman MS, Al-Zooba EM. Saudi Med J. 2003 May;24(5):499-503.

14. Goldfarb M, Rodgers SS, Lew JI. Appropriate surgical procedure for dominant thyroid nodules of the isthmus $1 \mathrm{~cm}$ or larger. Arch Surg. 2012 Sep;147(9):881-4. doi: 10.1001/archsurg.2012.728.

15. Najum ul Haq R, Ali Khan B, Ahmed Chaudhry I. Prevalence of malignancy in goitre-a review of 718 thyroidectomies. J Ayub Med Coll Abbottabad 2009; 21(4).

\footnotetext{
Author's contribution: manuscript.

Orcid ID:

Dr. Shib Shankar Kuiri:@ http://orcid.org/0000-0003-2212-6571

Dr. Nibaran Mandal:@ http://orcid.org/0000-0001-5577-698X

Dr. Yash Sharma: http://orcid.org/0000-0002-4038-5537
}

NM - Manuscript preparation, critical revision of manuscript, reviewed the literature; SSK - Conceptualized the study literature search, prepared first draft of manuscript, and critical revision of manuscript; MMN - literature search, statically analyzed and interpreted; BCG- concept of study, reviewed the study; GG - Concept and design of study, reviewed the literature and revision of manuscript; YS - Literature search, collected data and help in preparing first draft of 